\title{
Specific microRNA signatures in exosomes of triple-negative and HER2-positive breast cancer patients undergoing neoadjuvant therapy within the GeparSixto trial
}

Ines Stevic ${ }^{1}$, Volkmar Müller ${ }^{2}$, Karsten Weber ${ }^{3}$, Peter A. Fasching ${ }^{4}$, Thomas Karn ${ }^{5}$, Frederic Marmé ${ }^{6}$ Christian Schem ${ }^{7}$, Elmar Stickeler ${ }^{8}$, Carsten Denkert ${ }^{9}$, Marion van Mackelenbergh ${ }^{10}$, Christoph Salat $^{11}$, Andreas Schneeweiss ${ }^{12}$, Klaus Pantel ${ }^{1}$, Sibylle Loibl ${ }^{3}$, Michael Untch ${ }^{13}$ and Heidi Schwarzenbach ${ }^{1 *}$

\begin{abstract}
Background: The focus of this study is to identify particular microRNA (miRNA) signatures in exosomes derived from plasma of 435 human epidermal growth factor receptor 2 (HER2)-positive and triple-negative (TN) subtypes of breast cancer (BC).

Methods: First, miRNA expression profiles were determined in exosomes derived from the plasma of 15 TNBC patients before neoadjuvant therapy using a quantitative TaqMan real-time PCR-based microRNA array card containing 384 different miRNAs. Forty-five miRNAs associated with different clinical parameters were then selected and mounted on microRNA array cards that served for the quantification of exosomal miRNAs in 435 BC patients before therapy and 20 healthy women. Confocal microscopy, Western blot, and ELISA were used for exosome characterization.

Results: Quantification of 45 exosomal miRNAs showed that compared with healthy women, 10 miRNAs in the entire cohort of BC patients, 13 in the subgroup of 211 HER2-positive BC, and 17 in the subgroup of 224 TNBC were significantly deregulated. Plasma levels of 18 exosomal miRNAs differed between HER2-positive and TNBC subtypes, and 9 miRNAs of them also differed from healthy women. Exosomal miRNAs were significantly associated with the clinicopathological and risk factors. In uni- and multivariate models, miR-155 ( $p=0.002, p=0.003$, respectively) and miR-301 ( $p=0.002, p=0.001$, respectively) best predicted pathological complete response ( $p C R$ ).
\end{abstract}

Conclusion: Our findings show a network of deregulated exosomal miRNAs with specific expression patterns in exosomes of HER2-positive and TNBC patients that are also associated with clinicopathological parameters and pCR within each BC subtype.

Keywords: MicroRNAs, Exosomes, Breast cancer, Triple negative, HER2-positive, Pathological complete response, Neoadjuvant therapy

\footnotetext{
* Correspondence: h.schwarzenbach@uke.de

${ }^{1}$ Department of Tumor Biology, University Medical Center

Hamburg-Eppendorf, Martinistraße 52, 20246 Hamburg, Germany

Full list of author information is available at the end of the article
}

(c) The Author(s). 2018 Open Access This article is distributed under the terms of the Creative Commons Attribution 4.0 International License (http://creativecommons.org/licenses/by/4.0/) which permits unrestricted use, distribution, and reproduction in any medium, provided you give appropriate credit to the original author(s) and the source, provide a link to the Creative Commons license, and indicate if changes were made. The Creative Commons Public Domain Dedication waiver (http://creativecommons.org/publicdomain/zero/1.0/) applies to the data made available in this article, unless otherwise stated. 


\section{Background}

Breast cancer $(\mathrm{BC})$ comprises several subtypes that are in clinical routine defined by estrogen receptor (ER), progesterone receptor (PR), and human epidermal growth factor receptor 2 (HER2) status. Each BC subtype exhibits varied responses to different therapeutic regimens. Triple-negative (TNBC) and HER2-positive tumors are associated with a worse prognosis, a more aggressive clinical outcome, and a higher risk for relapse than luminal-like tumors that are positive for hormone receptors [1].

Since particular microRNA (miRNA) signatures are associated with BC subtypes and aggressiveness, as well as patient response to drug therapy and clinical outcome $[2,3]$, they open up new approaches for the development of non-invasive diagnostic and therapeutic tests. The deregulated expression of miRNAs in cancer may among others be caused by their frequent location in fragile chromosomal regions harboring DNA amplifications, deletions or translocations [4]. As evolutionary conserved family, these small non-coding RNA molecules inhibit post-transcriptionally gene expression by binding to complementary sequences in the $3^{\prime}$ untranslated-region (3'UTR) of their target mRNAs [5]. MiRNAs circulate highly stable in human blood [6]. They are released into the blood circulation either passively by apoptosis and necrosis or actively by exosomes from multiple cell types $[7,8]$. The process of sorting and packaging of miRNAs into exosomes depends on the cell origin, and is selective, favoring certain miRNAs for exosomal cargo to others $[9,10]$. Exosomes are small membrane vesicles in size of 30-100 $\mathrm{nm}$ [11]. They can mediate cell-to-cell communication by transferring proteins, lipids, and nucleic acids between donor and recipient cells, resulting possibly in modulation of the recipient cells. It is assumed that tumor-derived exosomes can transform normal, wild-type cells into malignant cells $[12,13]$. In this manner, they stimulate cellular signaling and regulate metabolic functions and homeostasis of hematopoietic cells $[14,15]$. MiRNAs derived from cancer-associated exosomes have been implicated in supporting or restraining tumor growth, conferring drug resistance, promoting recurrence, and preparing a metastatic niche [10]. Considering their biologic relevance, strategies to interfere with loading or delivery of exosomal oncogenic miRNAs might be used as a therapeutic approach.

Currently, TNBC is a focus of intense research since treatment options beyond chemotherapy are urgently required. In contrast, many options for HER2-positive patients exist but the optimal combination strategies are unclear, and clarifying the mechanisms of resistance is required. In both settings, it is important to improve the insights into the biology of tumor progression in the context of therapy. Neoadjuvant treatment strategies offer short-term results of treatment efficacy by evaluation of pathological complete response (pCR). Since this response is associated with long-term outcome, the treatment strategy is now used for the clinical evaluation of treatment strategies in $\mathrm{BC}$ patients.

In this study, we determined the expression of miRNA profiles in circulating exosomes of $\mathrm{BC}$ patients before neoadjuvant therapy within a randomized phase II neoadjuvant GeparSixto trial using quantitative TaqMan real-time PCR-based microRNA array cards. We detected a significant difference in the exosomal miRNA patterns between TNBC and HER2-positive patients. The packaging of particular miRNAs in exosomes was associated with clinicopathological and risk factors, and predicted $\mathrm{pCR}$.

\section{Methods}

\section{Study populations}

Within the multicenter GeparSixto trial from August 2011 to December 2012, BC patients were randomized to receive 18 weeks of neoadjuvant treatment with paclitaxel (80 $\mathrm{mg} / \mathrm{m}^{2} /$ week) and non-pegylated liposomal doxorubicin $\left(20 \mathrm{mg} / \mathrm{m}^{2} /\right.$ week $)$ with or without addition of carboplatin (AUC 2.0-1.5/week) [16]. Hormone-receptor status, HER2 status, and Ki67 expression were centrally confirmed prior to randomization. Plasma samples of 211 HER2-positive and 224 TNBC patients were collected directly before neoadjuvant therapy. After therapy, plasma samples of 4 HER2-positive and 5 TNBC patients were available. Median age of BC patients was 47 years and ranged from 21 to 78 years. Detailed patient characteristics are summarized in Table 1 (categorial variables) and Additional file 1: Table S1 (continuous variables). During 2016, plasma samples were collected from 20 healthy women with no history of cancer and in good health based on self-report (median age 55, range 47 to 69). Regarding blood processing, uniform management concerning the specific described protocols was performed. Blood collection and experiments were performed in compliance with the Helsinki Declaration and were approved by the ethics committee (Ethik-Kommission der Ärztekammer Hamburg, Hamburg). Plasma samples from $435 \mathrm{BC}$ patients and 20 healthy women were analyzed with different techniques as described below, and sample flow is depicted in Fig. 1.

\section{Verification of hemolysis in plasma samples}

To avoid quantifying exosomal miRNAs in hemolytic plasma samples that may influence our results, we performed hemoglobin measurements by spectral analysis [17]. In $7 \mathrm{ml}$ of whole blood, red blood cells were lysed by erythrocyte lysis buffer (containing $0.3 \mathrm{M}$ sucrose, $10 \mathrm{mM}$ Tris $\mathrm{pH} 7.5,5 \mathrm{mM} \mathrm{MgCl} 2$ and $1 \%$ Triton X100). A dilution series $(1: 1,1: 3,1: 4,1: 6,1: 8,1: 10,1: 12,1: 14$, 
Table 1 Breast cancer patient characteristics (categorial variables)

\begin{tabular}{|c|c|c|c|c|c|c|}
\hline \multicolumn{2}{|l|}{ Parameters } & \multirow{2}{*}{$\begin{array}{l}\text { All BC patients } \\
\text { analyzed in this study } \\
435(100.0 \%)\end{array}$} & \multirow{2}{*}{$\begin{array}{l}\text { HER2-positive patients } \\
211(100.0 \%)\end{array}$} & \multirow{2}{*}{$\begin{array}{l}\text { TNBC patients } \\
244(100.0 \%)\end{array}$} & \multirow{2}{*}{$\begin{array}{l}\text { All BC patients in } \\
\text { GeparSixto trial } \\
588(100.0 \%)\end{array}$} & \multirow[t]{2}{*}{$p$ value $^{*}$} \\
\hline Total & & & & & & \\
\hline \multirow[t]{2}{*}{ Subtype } & $\begin{array}{l}\text { HER2-positive } \\
\text { patients }\end{array}$ & $211(48.5 \%)$ & \multirow{2}{*}{\multicolumn{2}{|c|}{$\begin{array}{l}\text { Subgroups of all BC patients analyzed in this } \\
\text { study }\end{array}$}} & $273(46.4 \%)$ & 0.0909 \\
\hline & TNBC patients & $224(51.5 \%)$ & & & $315(53.6 \%)$ & \\
\hline \multirow[t]{2}{*}{ Age } & $<50$ & $249(57.2 \%)$ & $120(56.9 \%)$ & $129(57.6 \%)$ & $341(58.0 \%)$ & 0.5684 \\
\hline & $\geq 50$ & $186(42.8 \%)$ & $91(43.1 \%)$ & $95(42.4 \%)$ & $247(42.0 \%)$ & \\
\hline \multirow[t]{3}{*}{ Lymph node metastasis } & No & $240(56.1 \%)$ & $106(50.7 \%)$ & $134(61.2 \%)$ & $338(58.7 \%)$ & 0.0333 \\
\hline & $\mathrm{N}+$ & $188(43.9 \%)$ & $103(49.3 \%)$ & 85 (38.8\%) & $238(41.3 \%)$ & \\
\hline & Missing & 7 & 2 & 5 & 12 & \\
\hline \multirow[t]{3}{*}{ Tumor size } & T1-2 & $365(84.3 \%)$ & $167(79.9 \%)$ & $198(88.4 \%)$ & $499(85.2 \%)$ & 0.3570 \\
\hline & T3-4 & 68 (15.7\%) & $42(20.1 \%)$ & $26(11.6 \%)$ & $87(14.8 \%)$ & \\
\hline & Missing & 2 & 2 & 0 & 2 & \\
\hline \multirow[t]{2}{*}{ Grading } & G1-2 & $151(34.7 \%)$ & $93(44.1 \%)$ & $58(25.9 \%)$ & $207(35.2 \%)$ & 0.6944 \\
\hline & G3 & $284(65.3 \%)$ & $118(55.9 \%)$ & $166(74.1 \%)$ & $381(64.8 \%)$ & \\
\hline \multirow{3}{*}{$\begin{array}{l}\text { Lymphocyte predominant } \\
\text { breast cancer }\end{array}$} & pos. & $108(25.1 \%)$ & $44(21.4 \%)$ & $64(28.6 \%)$ & $142(24.4 \%)$ & 0.5825 \\
\hline & neg. & $322(74.9 \%)$ & $162(78.6 \%)$ & $160(71.4 \%)$ & $439(75.6 \%)$ & \\
\hline & Missing & 5 & 5 & 0 & 7 & \\
\hline \multirow[t]{2}{*}{ Therapy arm } & PM & $222(51.0 \%)$ & 109 (51.7\%) & $113(50.4 \%)$ & $293(49.8 \%)$ & 0.3478 \\
\hline & $\mathrm{PMCb}$ & $213(49.0 \%)$ & $102(48.3 \%)$ & $111(49.6 \%)$ & $295(50.2 \%)$ & \\
\hline \multirow{2}{*}{$\begin{array}{l}\text { Pathological complete } \\
\text { response ( } \mathrm{pCR})\end{array}$} & Yes & $223(51.3 \%)$ & $113(53.6 \%)$ & $110(49.1 \%)$ & $296(50.3 \%)$ & 0.4540 \\
\hline & No & $212(48.7 \%)$ & 98 (46.4\%) & 114 (50.9\%) & $292(49.7 \%)$ & \\
\hline
\end{tabular}

PM non-carboplatin treatment arm, $P M C b$ carboplatin treatment arm

${ }^{*}$ Characteristics of patients were compared between patients with analyzed samples and all patients of GeparSixto study (modified intend-to-treat population) using Fisher's exact tests

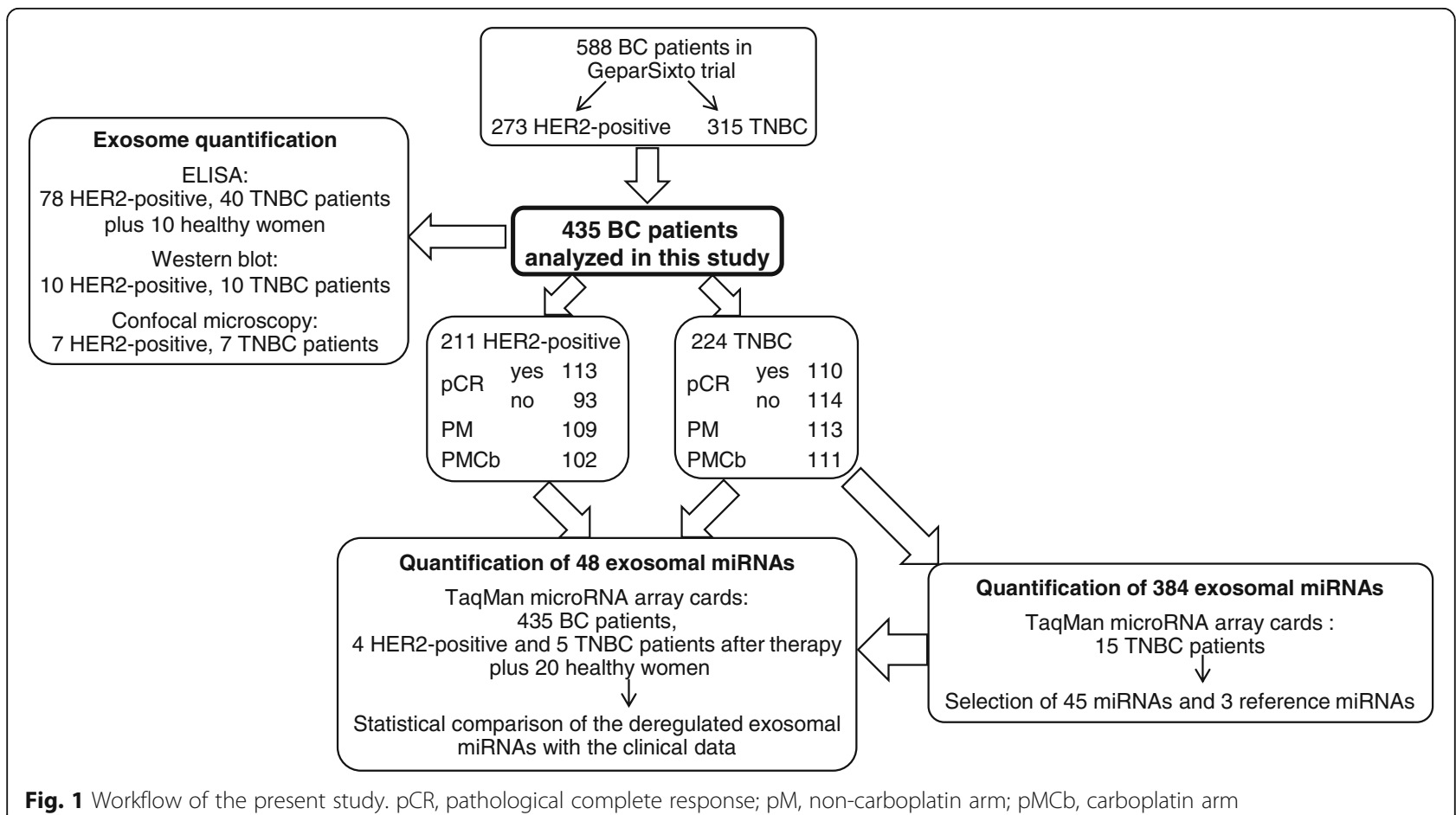

Fig. 1 Workflow of the present study. pCR, pathological complete response; pM, non-carboplatin arm; pMCb, carboplatin arm 
1:18, 1:20) of lysed red blood cells in plasma was prepared that served as a standard curve for the measurement of hemolysis in all plasma samples. Fifty microliters of each plasma sample (standard and plasma of interest) was measured in duplicates on a Microplate reader (Tecan, Männerdorf, Switzerland). Absorbance peaks at 414, 541, and $576 \mathrm{~nm}$ were indicative for free hemoglobin, with the highest peak at $414 \mathrm{~nm}$. The higher the absorbance in samples is, the higher is the degree of hemolysis. The average values and standard deviations were calculated from the duplicates (see Additional file 1: Figure S1).

\section{Isolation of total exosomes from plasma}

Total exosomes were isolated by ExoQuick (BioCat, Heidelberg, Germany) according to the manufacturer's instructions. Briefly, $550 \mu \mathrm{l}$ of plasma, removed from cells and debris by two centrifugation steps at $3000 \mathrm{~g}$ for $15 \mathrm{~min}$, was incubated with $120 \mu \mathrm{l}$ ExoQuick exosome precipitation solution at $4{ }^{\circ} \mathrm{C}$, for $30 \mathrm{~min}$. Following centrifugation at $1500 \mathrm{~g}$ for $30 \mathrm{~min}$, the exosomes were precipitated and then resuspended in $50 \mu \mathrm{l}$ PBS (phosphate-buffered saline) buffer (Life Technologies, Darmstadt, Germany).

\section{Visualization of exosomes using confocal microscopy}

The isolated exosomes were labeled by the Exo-GLOW Exosome Labeling Kits (System Biosciences, Palo Alto, California, USA). Five hundred-microliter resuspended exosomes and $50 \mu$ l Exo-Red in PBS were incubated at $37^{\circ} \mathrm{C}$ for $10 \mathrm{~min}$. The labeling reaction was stopped with $100 \mu \mathrm{l}$ ExoQuick-TC reagent at $4{ }^{\circ} \mathrm{C}$ for $30 \mathrm{~min}$. After centrifugation for $3 \mathrm{~min}$ at $14,000 \mathrm{rpm}$, the labeled exosome pellet was resuspended in $500 \mu \mathrm{l}$ PBS and monitored under a confocal microscope Leica sp5 with a $63 \mathrm{x}$ magnification using the 1.4 oil objective lens (Leica Microsystems, Wetzlar, Germany).

\section{ELISA}

Exosomes were quantified by the Exosome Antibodies \& ELISA Kit (System Biosciences), which is specific for the exosomal protein CD63. For performing ELISA, $400 \mu \mathrm{l}$ plasma was purified from fibrin by adding $4 \mu \mathrm{l}$ thrombin (BioCat, Heidelberg, Germany) at a final concentration of $5 \mathrm{U} / \mathrm{ml}$. Following exosome extraction by ExoQuick, $50 \mu \mathrm{l}$ exosome resuspension in duplicate and CD63 protein standards (undiluted, diluted 1:2, 1:4, 1:8, 1:16, 1:32 and 1:64) were added to the micro-titer plate (Tecan). The absorbance at $450 \mathrm{~nm}$ of the samples was measured on a spectrophotometric plate reader (Tecan), and the amounts of CD63 protein were calculated according to the exosome protein standard curve.

\section{Western blot}

To calculate the adequate protein amounts for carrying out a Western blot, the protein concentrations were at first measured with the DC Protein Assay Kit (BioRad, Munich, Germany) at a wavelength of $650 \mathrm{~nm}$ on a spectrophotometric plate reader (Tecan). A standard curve of $0,0.625,1.25,2.5,5$, and $10 \mathrm{mg} / \mathrm{ml} \mathrm{BSA}$ (bovine serum albumin; Sigma Aldrich Chemie, Munich, Germany) was applied by the double-dilution method. Five microliters of exosomes, exosome supernatant, and BSA (Sigma Aldrich Chemie) standard protein samples, all solved in RIPA buffer (Merck, Darmstadt, Germany), were added to 96-well plates according to the manufacturer's instructions. The protein concentrations were then calculated according to a linear equation by applying the regression method.

Exosomes were lysed in RIPA buffer (Merck) and PBS (Life Technologies), and $30 \mu \mathrm{g}$ of proteins from exosomes and exosome supernatant were electrophoretically separated and blotted onto a PVDF membrane (Millipore, Billerica, USA) which was subsequently incubated with antibodies specific for CD63 (ABGENT, San Diego, California, USA), CD81 (Invitrogen, Darmstadt, Germany) and AGO2 (TAKARA BIO INC, Shiga, Japan) overnight. Detection of the proteins was carried out using peroxidase-conjugated secondary antibodies (Dako, Glostrup, Denmark) and the chemiluminescence ECL detection solution (Sigma-Aldrich, St. Louis, MO, USA).

\section{Extraction of miRNAs and conversion into CDNA}

MiRNAs were extracted from $50 \mu \mathrm{l}$ exosomes resuspended in $150 \mu \mathrm{l}$ lysis buffer by using the TaqMan microRNA ABC Purification Kit (Thermo Fisher Scientific, Darmstadt, Germany) according to the manufacturer's recommendations. The extracted miRNAs were immediately reverse transcribed into cDNA using a modified protocol of TaqMan MicroRNA Reverse Transcription kit (Thermo Fisher Scientific). The 15- $\mu$ l reaction containing $6 \mu \mathrm{l}$ Custom RT primer pool, $0.3 \mu \mathrm{l}$ $100 \mathrm{mM}$ dNTPs with dTTP, $3 \mu \mathrm{l} 50 \mathrm{U} / \mu \mathrm{l}$ MultiScribe Reverse Transcriptase, $1.5 \mu \mathrm{l} 10 \times$ RT buffer, $0.19 \mu \mathrm{l}$ $20 \mathrm{U} / \mu \mathrm{l}$ RNase Inhibitor (Thermo Fisher Scientific), and $4 \mu \mathrm{l}$ extracted RNA was carried out at $16{ }^{\circ} \mathrm{C}$ for $30 \mathrm{~min}$, $42{ }^{\circ} \mathrm{C}$ for $30 \mathrm{~min}$, and $85^{\circ} \mathrm{C}$ for $5 \mathrm{~min}$ on a MJ Research PTC-200 Peltier Thermal Cycler (Global Medical Instrumentation, Ramsey, Minnesota, USA). The cDNA samples were stored at $-20^{\circ} \mathrm{C}$ for future use.

\section{Preamplification of miRNAs}

To increase the input cDNA, a preamplification step of cDNA was included. Five-microliter cDNA was preamplified in a $25-\mu \mathrm{l}$ reaction containing 12.5- $\mu \mathrm{l}$ TaqMan PreAmp Master Mix and 3.75- $\mu$ l Custom PreAmp Primer Pool (Thermo Fisher Scientific). PCR was run on a MJ 
Research PTC-200 Peltier Thermal Cycler (Global Medical Instrumentation): 1 cycle at $95{ }^{\circ} \mathrm{C}$ for $10 \mathrm{~min}, 55{ }^{\circ} \mathrm{C}$ for $2 \mathrm{~min}$, and $72{ }^{\circ} \mathrm{C}$ for $2 \mathrm{~min} ; 16$ cycles at $95{ }^{\circ} \mathrm{C}$ for $15 \mathrm{~s}$ and $60{ }^{\circ} \mathrm{C}$ for $4 \mathrm{~min}$; and a terminal cycle $99.9{ }^{\circ} \mathrm{C}$ for $10 \mathrm{~min}$. To avoid false-positive data (e.g., primer dimer formation or unspecific PCR products), a negative control without any templates was included from the starting point of all experiments.

\section{MiRNA expression profiling}

To identify differentially expressed miRNAs, real-time TaqMan PCR was at first carried out by using the TaqMan microRNA array Human Pool A cards containing 384 different miRNAs (Thermo Fisher Scientific), and plasma samples from 15 TNBC patients treated with/ without chemotherapy and with/without pathological response (pCR). Subsequently, microRNA array cards (Thermo Fisher Scientific) mounted with the 45 most significantly deregulated miRNAs derived from the above array card and 2 endogenous reference miRNAs (miR-92a and miR-484) as well as 1 exogenous control miRNA (cel-miR-39) for data normalization were quantified in plasma of $435 \mathrm{BC}$ patients and 20 healthy women by real-time TaqMan PCR. To carry out real-time TaqMan PCR, the protocol of Thermo Fisher Scientific was modified as followed: The 112.5- $\mu$ l PCR reaction containing 56.25- $\mu$ l TaqMan Universal Master Mix II and 2- $\mu \mathrm{l}$ preamplification product was loaded on the array cards. PCR was run on a 7300 HT 384 block (Applied Biosystems): 1 cycle at $95{ }^{\circ} \mathrm{C}$ for $10 \mathrm{~min}$ and 40 cycles at $95{ }^{\circ} \mathrm{C}$ for $15 \mathrm{~s}, 60^{\circ} \mathrm{C}$ for $1 \mathrm{~min}$.

Following 45 miRNAs were selected: snRNU6, let-7g, miR-16, miR-20a, miR-27a, miR-27b, miR-30c, miR-99b, miR-106b, miR-125b, miR-128a, miR-143, miR-145, miR-148a, miR-150, miR-152, miR-155, miR-181a, miR-185, miR-193b, miR-199a-3p, miR-202, miR-301, miR-324-3p, miR-328, miR-335, miR-340, miR-365, miR-370, miR-374, miR-376a, miR-376c, miR-382, miR-410, miR-422a, miR-423-5p, miR-433, miR-489, miR-511, miR-598, miR-628-5p, miR-652, miR-660, miR-744, miR-891a.

As tested by the Genorm Algorithm software, miR-92a and miR-484 provided evidence to be the most suitable reference miRNAs for data normalization.

\section{Data normalization and statistical analyses}

The statistical analyses were performed using the Thermo Fisher Scientific Analysis Software, Relative Quantification Analysis Module, version 3.1 (https://www.thermofisher.com/de/de/home/cloud.html), SPSS software package, version 22.0 (SPSS Inc. Chicago, Illinois, USA) and Statistical Programing Language R, version 3.3.2 (R Core Team 2016, Vienna, Austria).
All raw real-time PCR data were imported into the Thermo Fisher Scientific Analysis Software. First, the amplification curves were manually checked due to their shape of the curve. If a curve was atypical, the $\mathrm{Cq}$ value was omitted from the analysis. Second, Cq values with a Cq confidence score below 0.95 were discarded. The $\mathrm{Cq}$ confidence score was calculated according to the algorithm implemented in the Thermo Fisher Scientific Analysis Software and describes how likely it is that an obtained Cq value actually comes from a proper amplification curve by assessing the quality of the exponential phase of the respective curve.

The cleaned data were calculated and evaluated by the $\Delta \mathrm{Cq}$ method as follows: $\Delta \mathrm{Cq}=$ value $\mathrm{Cq}$ (miRNA of interest) - mean value $\mathrm{Cq}$ (reference miR-92a and miR-484). Surprisingly, snRNU6 was not detectable in most plasma samples and could not be used as a normalizer. According to the Genorm Algorithm software, most suitable reference miRNA were miR-92a and miR-484 for data normalization. Thus, normalization of miRNAs of interest was performed with these reference miRNAs [18]. Exogenous cel-miR-39 which was spiked in the plasma samples served as a control for the isolation process.

The Thermo Fisher Scientific Analysis software was used for performing hierarchical clustering (heat map) and Volcano plots. For the heat map, distances between samples and assays were calculated using unsupervised hierarchical clustering based on the $\Delta \mathrm{Cq}$ values and Pearson's correlation. Clustering method was average linkage. The Volcano plot displays the $p$ value versus the fold change for each target in the patient group of interest (BC patient group, HER2-positive or TNBC subgroups) relative to a reference group (healthy group or even HER2-positive subgroup). Here, $\Delta \Delta \mathrm{Cq}$ was calculated as mean $\Delta \mathrm{Cq}$ (miRNA of interest in the group of interest) - mean of $\triangle \mathrm{Cq}$ (miRNA of interest in the reference group). Then, the relative quantification ( $\mathrm{Rq}$ or gene expression fold change) was calculated as $2^{-(\Delta \Delta \mathrm{Cq})} . \Delta \mathrm{Cq}$ values were used to calculate $p$ values using unpaired two-tailed student $t$ test, and assuming unequal variances. Subsequently, the relative expression data $(\mathrm{Rq})$ and $p$ values adjusted for multiple testing by Benjamini and Hochberg method were $\log 2$ and $\log 10$-transformed, respectively, and plotted as a volcano plot.

Box plots for the ELISA values of exosomes and data of miRNAs, as well as receiver operating characteristic (ROC) curves, were carried out by the SPSS (version 22) software. For nonparametric comparisons of two dependent and independent variables, miRNA levels before and after therapy and differences in group levels were compared by Wilcoxon and Mann-Whitney $U$ tests, respectively.

Fisher's exact and Mann-Whitney $U$ tests were carried out for categorial variables (Table 1) and continuous 
variables (see Additional file 1: Table S1), respectively. Differences of miRNA levels among the (sub)-groups were calculated using the two-tailed Student $t$ test (Table 2). Associations between miRNA levels and dichotomous clinical variables were analyzed by calculating the difference of mean $\Delta \mathrm{Cq}$ values among clinical groups and using an unpaired Student's $t$ test (Table 3).
Correlations between miRNA levels and continuous clinical variables are presented by Pearson's correlation coefficients (see Additional file 1: Table S2). No multiple test correction was applied to the $p$ values in Table 3 and Additional file 1: Table S2. The dependency of pCR on miRNA levels, represented by $\Delta \mathrm{Cq}$ values, was estimated from logistic regression models: For each miRNA

Table 2 Significantly deregulated exosomal miRNAs in plasma of HER2-positive and TNBC patients

\begin{tabular}{|c|c|c|c|c|}
\hline \multirow[t]{2}{*}{ miRNAs } & $\begin{array}{l}\text { All patients analyzed } \\
\text { in this study } \\
\text { vs. Healthy women }\end{array}$ & $\begin{array}{c}\text { HER2-positive } \\
\text { patients } \\
\text { vs. Healthy women }\end{array}$ & $\begin{array}{l}\text { TNBC patients } \\
\text { vs. Healthy } \\
\text { women }\end{array}$ & $\begin{array}{c}\text { TNBC patients } \\
\text { vs. Her2-positive } \\
\text { patients }\end{array}$ \\
\hline & \multicolumn{4}{|c|}{$p$-value (fold change) } \\
\hline let-7g & - & - & - & $p=0.020(1.3)$ \\
\hline miR-16 & - & - & - & $p=0.023(0.8)$ \\
\hline miR-27a & $p=0.020(1.7)$ & $p=0.004(1.9)$ & - & $p=0.009(0.8)$ \\
\hline miR-27b & $p=0.010(2.3)$ & $p=0.001(2.8)$ & $\mathrm{p}=0.021(1.9)$ & $p<0.0001(0.7)$ \\
\hline miR-30c & $p=0.040(0.7)$ & $p=0.032(0.7)$ & $p=0.035(0.7)$ & - \\
\hline miR-128a & - & - & $p=0.048(1.6)$ & - \\
\hline miR-143 & - & - & - & $p<0.0001(0.6)$ \\
\hline miR-145 & - & - & $p=0.036(1.6)$ & - \\
\hline miR-148a & - & - & - & $\mathrm{p}<0.0001(2.0)$ \\
\hline miR-150 & $p=0.020(0.6)$ & $p=0.007(0.5)$ & $p=0.028(0.6)$ & - \\
\hline miR-152 & $p=0.010(1.9)$ & $p=0.005(1.9)$ & $p=0.004(1.9)$ & - \\
\hline miR-199a-3p & $p=0.010(3.9)$ & $p=0.005(3.9)$ & $p=0.005(3.9)$ & - \\
\hline miR-202 & - & - & - & $p=0.0001(2.4)$ \\
\hline miR-324-3p & - & - & $p=0.040(2.3)$ & - \\
\hline miR-328 & - & $p=0.035(1.6)$ & - & - \\
\hline miR-335 & - & - & $p=0.028(2.5)$ & $p<0.0001(1.8)$ \\
\hline miR-340 & $p=0.040(3.0)$ & $p=0.039(2.7)$ & $p=0.017(3.3)$ & - \\
\hline miR-365 & - & $p=0.005(1.9)$ & - & $p<0.0001(0.6)$ \\
\hline miR-370 & - & - & - & $p=0.023(1.5)$ \\
\hline miR-376a & $p=0.040(2.6)$ & - & $p=0.011(3.0)$ & - \\
\hline $\mathrm{miR}-376 \mathrm{c}$ & - & - & $p=0.006(2.1)$ & $p<0.0001(1.6)$ \\
\hline miR-382 & - & - & $p=0.011(2.7)$ & $p<0.0001(1.7)$ \\
\hline miR-410 & $p=0.030(2.1)$ & $p=0.023(2.1)$ & $p=0.017(2.2)$ & - \\
\hline $\mathrm{miR}-422 \mathrm{a}$ & - & $p=0.011(0.2)$ & - & $p<0.0001(3.0)$ \\
\hline miR-423-5p & - & - & $p=0.036(1.5)$ & - \\
\hline miR-433 & - & - & $p=0.025(2.3)$ & $p=0.001(1.5)$ \\
\hline miR-489 & - & - & - & $p=0.007(1.6)$ \\
\hline miR-598 & $\mathrm{p}=0.040(2.8)$ & $\mathrm{p}=0.028(2.8)$ & $p=0.028(2.8)$ & - \\
\hline miR-628 & - & $p=0.049(0.15)$ & - & $p<0.0001(2.6)$ \\
\hline miR-652 & - & - & - & $p<0.0001(1.9)$ \\
\hline miR-891a & - & - & - & $\mathrm{p}=0.0001(2.7)$ \\
\hline
\end{tabular}

Cells filled with "-" denote insignificant correlations

Exosomal miRNAs levels which are deregulated in one or both subgroups and additionally differ between the two subgroups of HER2-positive and TNBC patients are marked in grey 
Table 3 Significant associations between the plasma levels of exosomal miRNAs and clinicopathological/risk parameters (categorial variables)

\begin{tabular}{|c|c|c|c|c|}
\hline $\begin{array}{l}\text { Clinical/risk } \\
\text { factors }\end{array}$ & miRNAs* & $\begin{array}{l}\text { All BC patients } \\
p(t \text { test })^{* *}\end{array}$ & $\begin{array}{l}\text { HER2-positive patients } \\
p(t \text { test })^{* *}\end{array}$ & $\begin{array}{l}\text { TNBC patients } \\
p(t \text { test })^{* *}\end{array}$ \\
\hline \multirow{10}{*}{$\begin{array}{l}\text { Age } \\
(<50, \geq 50)\end{array}$} & miR-20a & 0.011 & - & - \\
\hline & miR-30c & - & - & 0.038 \\
\hline & miR-99b & 0.006 & - & 0.002 \\
\hline & miR-106b & 0.024 & - & - \\
\hline & miR-145 & 0.015 & - & 0.040 \\
\hline & miR-150 & 0.008 & - & 0.015 \\
\hline & miR-185 & 0.035 & - & - \\
\hline & miR-202 & 0.046 & - & - \\
\hline & miR-301 & 0.019 & 0.032 & - \\
\hline & miR-891a & 0.007 & - & 0.010 \\
\hline \multirow{3}{*}{$\begin{array}{l}\text { Nodal status } \\
(\mathrm{N} 0, \mathrm{~N}+)\end{array}$} & miR-16 & - & 0.023 & - \\
\hline & miR-328 & - & 0.019 & - \\
\hline & miR-660 & - & 0.016 & - \\
\hline \multirow{8}{*}{$\begin{array}{l}\text { Tumor size } \\
(\mathrm{T} 1-2, \mathrm{~T} 3-4)\end{array}$} & miR-185 & - & 0.040 & - \\
\hline & miR-199a-3p & 0.034 & - & - \\
\hline & miR-374 & - & - & 0.030 \\
\hline & miR-376a & - & 0.004 & - \\
\hline & miR-382 & 0.031 & 0.014 & - \\
\hline & miR-410 & - & 0.038 & - \\
\hline & miR-433 & - & 0.037 & - \\
\hline & miR-628-5p & - & 0.041 & - \\
\hline \multirow{7}{*}{$\begin{array}{l}\text { Grading } \\
(\mathrm{G} 1-2, \mathrm{G} 3)\end{array}$} & miR-16 & 0.033 & - & - \\
\hline & miR-20a & 0.024 & - & 0.032 \\
\hline & miR-30c & - & - & 0.023 \\
\hline & miR-155 & - & - & 0.038 \\
\hline & miR-193b & - & - & 0.028 \\
\hline & miR-422a & - & 0.010 & - \\
\hline & miR-628-5p & - & 0.005 & - \\
\hline \multirow{4}{*}{$\begin{array}{l}\text { Lymphocyte } \\
\text { predominant } \\
\text { breast cancer } \\
\text { (neg, pos) }\end{array}$} & miR-148a & 0.036 & - & - \\
\hline & miR-335 & 0.048 & - & - \\
\hline & miR-652 & - & 0.040 & - \\
\hline & miR-891a & 0.050 & 0.022 & - \\
\hline
\end{tabular}

Cells filled with "-" denote insignificant correlations

*Only miRNAs are listed which significantly correlate with the clinical parameter in one of the (TNBC and HER2-positive) patient subgroups and/or all patients ${ }^{* *} p(t$ test $)$, Student's $t$ test

and each subgroup (all patients, HER2-positive patients, TNBC patients, and patients in the treatment arm), a univariate model as well as a multivariate model including the covariables age (continuous), nodal status (N0 vs. $\mathrm{N}+$ ), tumor size (T1-2 vs. T3-4), and grading (G1-2 vs. G3) were calculated, and the odd ratio with the $95 \%$ confidence interval and the associated Wald $p$ value for the miRNA are presented (Table 4 ). A $p$ value $<0.05$ was considered as statistically significant. All $p$ values are two-sided.

\section{Results}

Higher levels of exosomes in the blood circulation of BC patients

First, we analyzed the exosomes by confocal microscopy, Western blot, and ELISA (Fig. 1). To visualize the 
Table 4 Logistic regression models for $p C R$ with $p$ values, odds ratio, and confidence intervals

\begin{tabular}{|c|c|c|c|c|c|c|c|}
\hline \multirow[t]{2}{*}{ miRNAs } & \multirow{2}{*}{$\begin{array}{l}\text { Patients } \\
\text { Model }\end{array}$} & \multicolumn{2}{|l|}{ All BC patients } & \multicolumn{2}{|c|}{ HER2-positive patients } & \multicolumn{2}{|l|}{ TNBC patients } \\
\hline & & Univariate & Multivariate & Univariate & Multivariate & Univariate & Multivariate \\
\hline \multirow[t]{3}{*}{ miR-20a } & All & - & - & - & - & - & - \\
\hline & In PM & - & - & - & - & - & - \\
\hline & In PMCb & $\begin{array}{l}p=0.020 \\
1.39(1.05-1.84)\end{array}$ & $\begin{array}{l}p=0.019 \\
1.41(1.06-1.89)\end{array}$ & - & - & - & - \\
\hline \multirow[t]{3}{*}{ miR-27b } & All & - & - & $\begin{array}{l}p=0.035 \\
1.30(1.02-1.65)\end{array}$ & $\begin{array}{l}p=0.050 \\
1.28(1.00-1.63)\end{array}$ & - & - \\
\hline & In PM & - & - & - & - & - & - \\
\hline & In PMCb & $\begin{array}{l}p=0.038 \\
1.27(1.01-1.59)\end{array}$ & $\begin{array}{l}p=0.030 \\
1.30(1.03-1.64)\end{array}$ & - & - & - & - \\
\hline \multirow[t]{3}{*}{ miR-99b } & All & $\begin{array}{l}p=0.103 \\
1.14(0.97-1.34)\end{array}$ & $\begin{array}{l}p=0.039 \\
1.19(1.01-1.41)\end{array}$ & - & - & - & - \\
\hline & In PM & - & - & - & - & - & - \\
\hline & in $\mathrm{PMCb}$ & - & - & - & - & - & - \\
\hline \multirow[t]{3}{*}{ miR-155 } & All & $\begin{array}{l}p=0.002 \\
1.25(1.08-1.44)\end{array}$ & $\begin{array}{l}p=0.003 \\
1.24(1.08-1.44)\end{array}$ & $\begin{array}{l}p=0.049 \\
1.24(1.00-1.53)\end{array}$ & $\begin{array}{l}p=0.035 \\
1.26(1.02-1.56)\end{array}$ & $\begin{array}{l}p=0.013 \\
1.29(1.05-1.57)\end{array}$ & $\begin{array}{l}p=0.018 \\
1.29(1.04-1.58)\end{array}$ \\
\hline & In PM & $\begin{array}{l}p=0.033 \\
1.26(1.02-1.55)\end{array}$ & $\begin{array}{l}p=0.049 \\
1.24(1.00-1.53)\end{array}$ & - & - & - & - \\
\hline & In PMCb & $\begin{array}{l}p=0.032 \\
1.24(1.02-1.51)\end{array}$ & $\begin{array}{l}p=0.023 \\
1.27(1.03-1.55)\end{array}$ & - & - & - & - \\
\hline \multirow[t]{3}{*}{ miR-193b } & All & $\begin{array}{l}p=0.039 \\
1.13(1.01-1.26)\end{array}$ & $\begin{array}{l}p=0.055 \\
1.12(1.00-1.26)\end{array}$ & $\begin{array}{l}p=0.010 \\
1.26(1.06-1.50)\end{array}$ & $\begin{array}{l}p=0.012 \\
1.26(1.05-1.51)\end{array}$ & - & - \\
\hline & In PM & - & - & - & - & - & - \\
\hline & In PMCb & - & - & - & - & - & - \\
\hline \multirow[t]{3}{*}{ miR-301 } & All & $\begin{array}{l}p=0.002 \\
1.25(1.08-1.44)\end{array}$ & $\begin{array}{l}p=0.001 \\
1.27(1.10-1.46)\end{array}$ & $\begin{array}{l}p=0.013 \\
1.30(1.06-1.60)\end{array}$ & $\begin{array}{l}p=0.011 \\
1.32(1.07-1.64)\end{array}$ & - & - \\
\hline & In PM & $\begin{array}{l}p=0.040 \\
1.22(1.01-1.48)\end{array}$ & $\begin{array}{l}p=0.028 \\
1.25(1.02-1.52)\end{array}$ & - & - & - & - \\
\hline & In PMCb & $\begin{array}{l}p=0.020 \\
1.28(1.04-1.57)\end{array}$ & $\begin{array}{l}p=0.022 \\
1.29(1.04-1.6)\end{array}$ & $\begin{array}{l}p=0.012 \\
1.53(1.10-2.12)\end{array}$ & $\begin{array}{l}p=0.016 \\
1.51(1.08-2 . .12)\end{array}$ & - & - \\
\hline \multirow[t]{3}{*}{ miR-365 } & All & - & - & - & - & - & - \\
\hline & In PM & - & - & $\begin{array}{l}p=0.052 \\
1.35(1.00-1.81)\end{array}$ & $\begin{array}{l}p=0.038 \\
1.39(1.02-1.90)\end{array}$ & - & - \\
\hline & In PMCb & - & - & - & - & - & - \\
\hline \multirow[t]{3}{*}{$m i R-423-5 p$} & All & $\begin{array}{l}p=0.048 \\
1.19(1.00-1.42)\end{array}$ & $\begin{array}{l}p=0.064 \\
1.18(0.99-1.41)\end{array}$ & - & - & - & - \\
\hline & In PM & - & - & - & - & - & - \\
\hline & In PMCb & - & - & - & - & - & - \\
\hline \multirow[t]{3}{*}{ miR-511 } & All & - & - & - & - & - & - \\
\hline & In PM & - & - & - & - & - & - \\
\hline & In PMCb & - & - & - & - & $\begin{array}{l}p=0.239 \\
0.90(0.76-1.07)\end{array}$ & $\begin{array}{l}p=0.043 \\
0.78(0.62-0.99)\end{array}$ \\
\hline \multirow[t]{3}{*}{ miR-628-5p } & All & - & - & - & - & $\begin{array}{l}p=0.024 \\
0.81(0.67-0.97)\end{array}$ & $\begin{array}{l}p=0.017 \\
0.79(0.65-0.96)\end{array}$ \\
\hline & In PM & - & - & - & - & - & - \\
\hline & In PMCb & - & - & - & - & - & - \\
\hline \multirow[t]{3}{*}{ miR-660 } & All & - & - & $\begin{array}{l}p=0.044 \\
1.35(1.01-1.80)\end{array}$ & $\begin{array}{l}p=0.027 \\
1.40(1.04-1.89)\end{array}$ & - & - \\
\hline & In PM & - & - & - & - & - & - \\
\hline & In PMCb & - & - & - & - & - & - \\
\hline
\end{tabular}


Table 4 Logistic regression models for $\mathrm{pCR}$ with $p$ values, odds ratio, and confidence intervals (Continued)

\begin{tabular}{|c|c|c|c|c|c|c|c|}
\hline \multirow[t]{2}{*}{ miRNAs } & \multirow{2}{*}{$\begin{array}{l}\text { Patients } \\
\text { Model }\end{array}$} & \multicolumn{2}{|l|}{ All BC patients } & \multicolumn{2}{|c|}{ HER2-positive patients } & \multicolumn{2}{|c|}{ TNBC patients } \\
\hline & & Univariate & Multivariate & Univariate & Multivariate & Univariate & Multivariate \\
\hline \multirow[t]{3}{*}{ miR-891a } & All & $\begin{array}{l}p=0.063 \\
1.07(1.00-1.15)\end{array}$ & $\begin{array}{l}p=0.036 \\
1.08(1.01-1.16)\end{array}$ & - & - & - & - \\
\hline & In PM & - & - & - & - & - & - \\
\hline & In $\mathrm{PMCb}$ & - & _- & - & - & - & - \\
\hline
\end{tabular}

Cells filled with "-" denote insignificant miRNA contributions to the models. MiRNAs which do not show significant contributions in any population were omitted. For each miRNA variable and each patient group, a univariate as well as a multivariate model with the covariables of age, nodal status, tumor size, and grading were calculated

The odds ratio with the $95 \%$ confidence interval and the associated Wald $p$ value for the miRNAs are presented

$P M$ non-carboplatin treatment arm, $P M C b$ carboplatin treatment arm

exosomes by confocal microscopy, we stained them in plasma of $14 \mathrm{BC}$ patients and healthy women with Exo-Red. As exemplarily shown in the wide-field fluorescence image, the labeled exosomes from a healthy woman, a $\mathrm{BC}$ patient, and supernatant are little red dots due to their sizes below the diffraction limit. Some more exosomes can be seen in the plasma of a BC patient than in a healthy woman. In the supernatant, we can also detect a few exosomes, but the level is very low (Fig. 2a). However, it should be kept in mind that these images show only one frame of the pool of exosomes and one time point. The extraction of exosomes from $20 \mathrm{BC}$ patients was also verified on a Western Blot using antibodies specific for the exosomal markers CD63 and CD81, as well as for AGO2. The AGO2-specific antibody recognized cell-free miRNAs bound to AGO2 protein (103-kDa band) in the exosome supernatant, but did not detect AGO2 in the non-lysed exosome pellet. These findings show that the exosome fraction may be pure and devoid of cell-free miRNAs. However, they do not exclude that exosomes may still contain traces of contaminations of cell-free AGO2-bound miRNAs that due to the sensitivity of the Western blot were not detectable. As expected in lysed exosomes, AGO2 protein could be detected; however, its

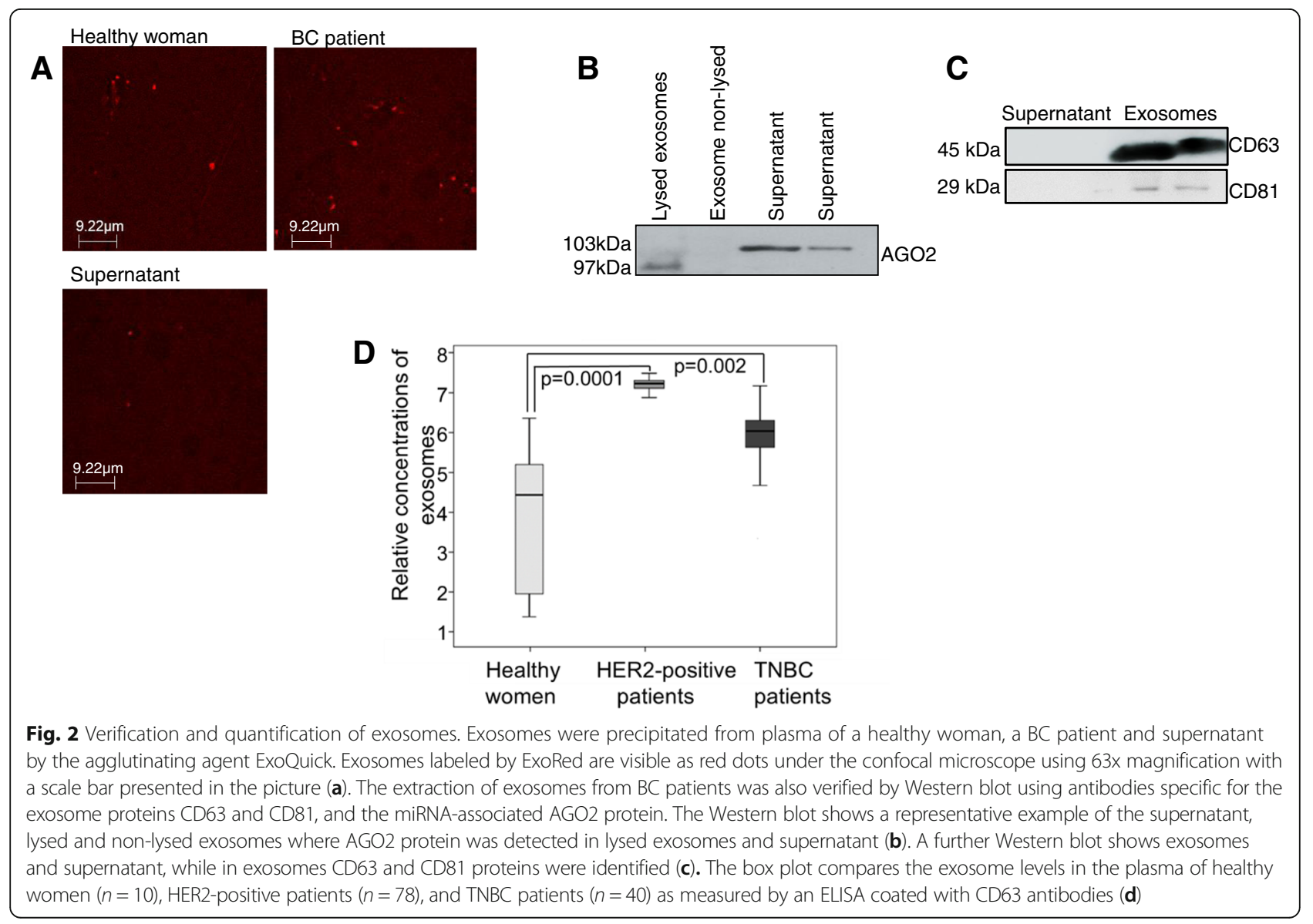


band was at size of around $97 \mathrm{kDa}$ and lower than its bands in the supernatant (Fig. 2b). This discrepancy can possibly be explained due to the fact that supernatant was differently treated and not lysed, and a high concentration of other proteins and contaminants are still available which could produce a shift in size. As described by the company, the AGO2-specific antibody recognizes a band at size of $103 \mathrm{kDa}$ which is detected in the supernatant. Moreover, Sharma et al. showed that the band is at size of $97 \mathrm{kDa}$ corresponding to our findings in the lysed exosomes [19]. However, further analyses have to be carried out to explain this inconsistency. As visible by the 45 and 29 kDa-bands, CD63- and CD81-specific antibodies recognized the non-lysed exosomes in the pellet, respectively, but did not detect any exosomes in the exosome supernatant (Fig. 2c). In contrast to the wide-field fluorescence images that show some exosomes in the supernatant and not in Western blot, these findings indicate that Western blot is not sensitive enough. We also quantified circulating exosomes from plasma of 78 HER2-positive and 40 TNBC patients using an ELISA coated with antibodies against the exosomal marker CD63, and compared their exosome levels with those of 10 healthy women. The exosome levels were significantly higher in HER2-positive ( $p=$ $0.0001)$ and TNBC patients $(p=0.002)$ than in healthy women, indicating an excessive, active secretion of exosomes in $\mathrm{BC}$ patients. Although the exosome levels were higher in HER2-positive patients than in TNBC patients, the difference between these two levels was not significant $(p=0.086$, Fig. $2 \mathrm{~d})$.

\section{Different exosomal miRNA signatures in HER2-positive and TNBC patients}

Following the qualitative and quantitative analyses of exosomes, we determined the miRNA expression profiles in exosomes derived from plasma of 15 TNBC patients before neoadjuvant therapy using a quantitative TaqMan real-time PCR-based microRNA array card containing 384 different miRNAs (Fig. 1). The patient group included 8 patients treated with carboplatin, (4 with $\mathrm{pCR}$ and 4 without $\mathrm{pCR}$ ), and 7 patients from the non-carboplatin arm (4 with $\mathrm{pCR}$ and 3 without $\mathrm{pCR}$ ). We aimed to select from the panel of 384 miRNAs those exosomal miRNAs which are most differentially expressed between the respective subgroups defined by pCR and treatment arm. While the plasma levels of only one exosomal miRNA (miR-199a, $p=0.036$ ) differed between patients with and without pCR, the levels of 4 exosomal miRNAs (miR-125, $p=0.029$; miR-193b, $p=$ 0.029; miR-365, $p=0.029$; miR-370, $p=0.016$ ) differed according to the treatment arm (data not shown). These 5 miRNAs and 40 additional miRNAs that were significantly associated with other clinical parameters (tumor size, nodal status, grading) were selected and mounted (together with two references and one exogenous control miRNA) on 48-microRNA array cards, and further analyzed in plasma from $435 \mathrm{BC}$ patients before treatment and 20 healthy women (Fig. 1). The complete list of miRNAs of this 48-microRNA array card is described in the "Methods" section. The $\Delta \mathrm{Cq}$ values of all $45 \mathrm{miR}$ NAs vs. the mean of references miR-92a and miR-484 among all 455 samples were median-centered and clustered by unsupervised hierarchical clustering based on average linkage and Pearson's correlation as distance metric. The resulting heatmap shows conspicuously an integrated dark green color of some columns on left side referring to the mean levels of exosomal miRNAs detected in plasma of healthy women suggesting there is no change in their miRNA expression in contrast to the patients. The color scale under the heat map represents $\Delta \mathrm{Cq}$ from the median of all data (see Additional file 1: Figure S2).

The volcano plots with the $\log 2$ fold changes plotted on the $x$-axis and the negative $\log 10 p$ values plotted on the $y$-axis show all down- (left side) and upregulated (right side) plasma levels of exosomal miRNAs in BC patients. As shown in Fig. 4, the plots compare the expression levels of exosomal miRNA in plasma of all $435 \mathrm{BC}$ patients (A) and the subgroups of 211 HER2-positive BC (B) and 224 TNBC patients (C) with those of 20 healthy women, as well as the levels between TNBC and HER2-positive BC patients (D). Compared with healthy women, we identified 8 up- (red dots) and 2 downregulated (green dots), 9 up- and 4 downregulated and 15 up- and 2 downregulated exosomal miRNAs in the entire cohort of $\mathrm{BC}$ patients (A), and in the subgroups of HER2-positive BC (B) and TNBC patients (C), respectively. The levels of 18 exosomal miRNAs differed between TNBC and HER2-positive BC patients, whereby 5 and 13 miRNAs were higher and lower in HER2-positive than in TNBC patients (D), respectively (Fig. 3).

Table 2 summarizes the significant results with the adjusted $p$ values and fold changes of miRNAs as derived from volcano plots (Fig. 3). From 45 miRNAs, 30 exosomal miRNAs were either differentially expressed in the subgroups of HER2-positive and TNBC patients, or in all $\mathrm{BC}$ patients compared with those of healthy women. Of particular interest are the relative differences of exosomal miRNA levels between HER2-positive and TNBC patients. From the 18 exosomal miRNAs, whose levels differed significantly between HER2-positive and TNBC patient subgroups, 9 miRNAs were also deregulated in one or both subgroups compared with healthy women (Table 2).

With respect to the subgroup, the significant differences between TNBC and HER2-positive patients were reflected by AUC values of $0.737,0.655$, and 0.759 for miR-335, miR-422a, and miR-628, respectively. To 


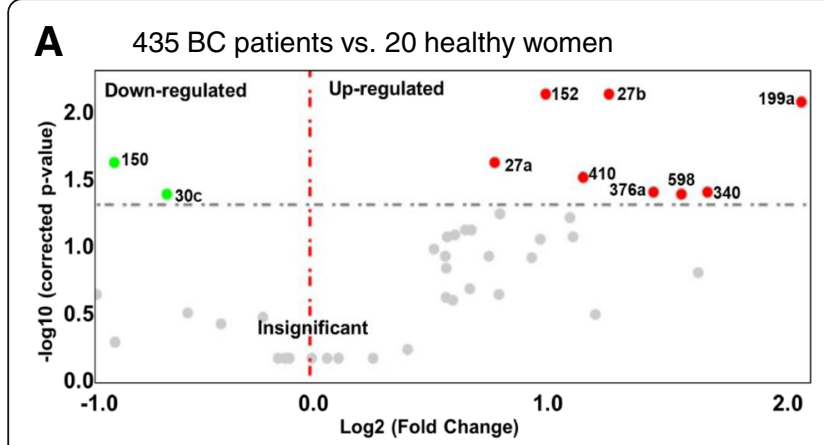

B $211 \mathrm{HER} 2-$ positive patients vs. 20 healthy women

C 224 TNBC patients vs. 20 healthy women
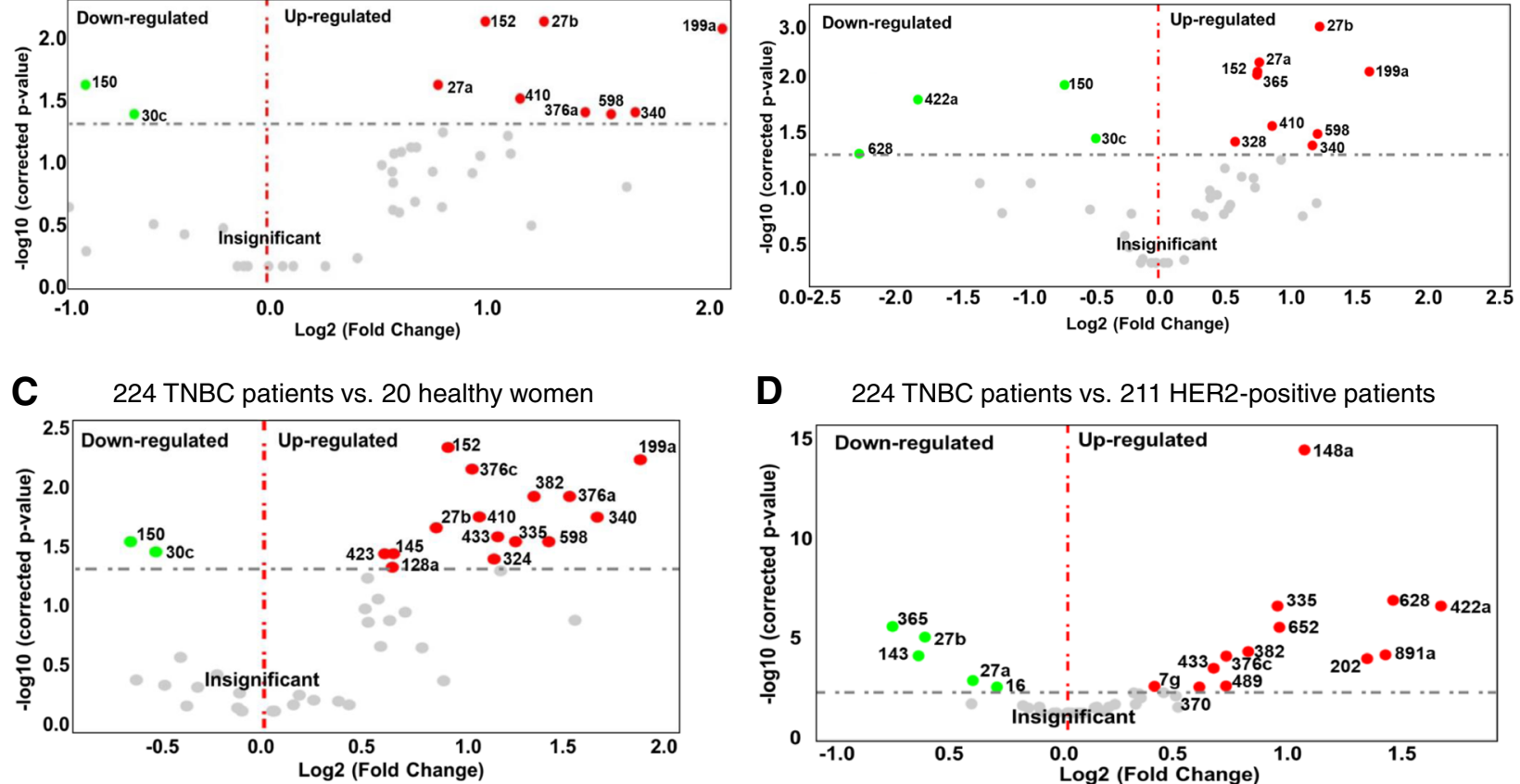

D 224 TNBC patients vs. 211 HER2-positive patients

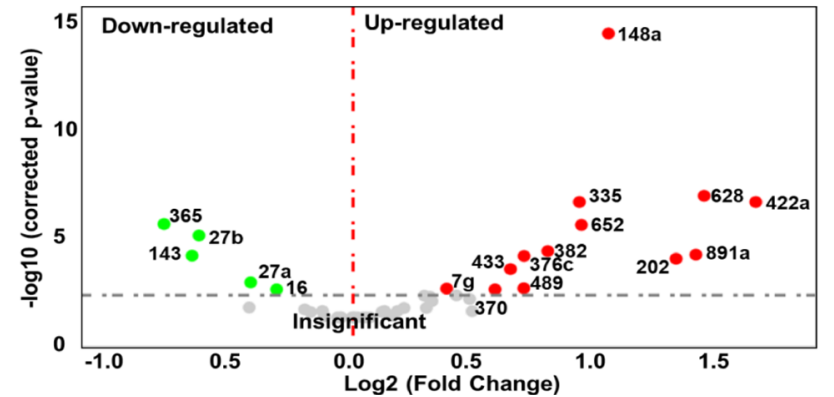

Fig. 3 Volcano plot of 45 exosomal miRNAs. Volcano plots of $p$ values vs fold changes compare the expression of exosomal miRNAs in 435 BC (a), 211 HER2-positive (b), and 224 TNBC patients (c) with that of 20 healthy women, as well as between HER2-positive and TNBC patients (d). The grey dashed line refers to the threshold value corresponding to a corrected $p$ value of $p=0.05$. Significantly downregulated exosomal miRNAs are shown as green dots, significantly upregulated exosomal miRNAs as red dots. Grey dots represent non-significant changes. $p$ values are calculated by the Student $t$ test and corrected according to the Benjamini and Hochberg method

improve the discrimination, the concentrations of exosomal miR-335 and miR-628 as well as miR-335, miR-422a, and miR-628 were combined by logistic regression. The combined scores of these exosomal miRNAs could discriminate between TNBC and HER2-positive patients with a sensitivity of $65 \%$ and $68 \%$ and a specificity of $84 \%$ and $81 \%$, respectively (these numbers may be biased towards higher values, because the scores were fitted on the same data). Sensitivities and specificities were determined at the highest Youden index (sensitivity + specificity -1 ) (see Additional file 1: Figure S3).

\section{Exosomal miRNA levels after neoadjuvant therapy}

Plasma samples from only 9 BC (4 HER2-positive and 5 TNBC) patients were available directly after neoadjuvant therapy before surgery (Fig. 1). To obtain information on changes in the plasma levels induced by the therapy, we compared the levels of exosomal miRNAs after therapy with those before therapy, and those of healthy women. Only 4 miRNAs (miR-27a, miR-155, miR-376a, and miR-376c) significantly changed their levels after therapy. Since the levels of the other miRNAs hardly differed between before and after therapy, the box plot and the table ( $p$ values) only show the dynamics of these 4 miRNAs (Fig. 4). Although the data are not representative because of the small number of $\mathrm{BC}$ patients, they nevertheless show that the decrease in the levels of 4 exosomal miRNAs to normal (healthy) levels after therapy may be affected by neoadjuvant therapy (Fig. 4). Unfortunately, the cohort of $9 \mathrm{BC}$ patients was too small to result in a robust statistical evaluation.

\section{Associations of exosomal miRNA levels with the established risk factors}

Table 3 (categorial variables) and Additional file 1: Table S2 (continuous variables) summarize the significant correlations between the exosomal miRNA levels and the clinicopathological risk parameters of $\mathrm{BC}$ patients. Strikingly, the levels of miRNAs in both subgroups (HER2-positive and TNBC) displayed a different preference to correlate with clinicopathogical parameters: With only one exception (miR-152 and stromal lymphocytes, see Additional file 1: Table S2), no miRNA correlated with a clinical parameter, such as nodal status, tumor size, grading, lymphocyte predominant BC, Ki67 expression, and intratumoral lymphocytes, in both subgroups. In particular, the levels of exosomal miR-16 ( $p=$ $0.23)$, miR-328 $(p=0.19)$, and miR-660 ( $p=0.016)$ were associated with lymph node status in HER2-positive patients (Table 3). Accordingly, the levels of exosomal miR-16 were lower in TNBC than in HER2-positive 


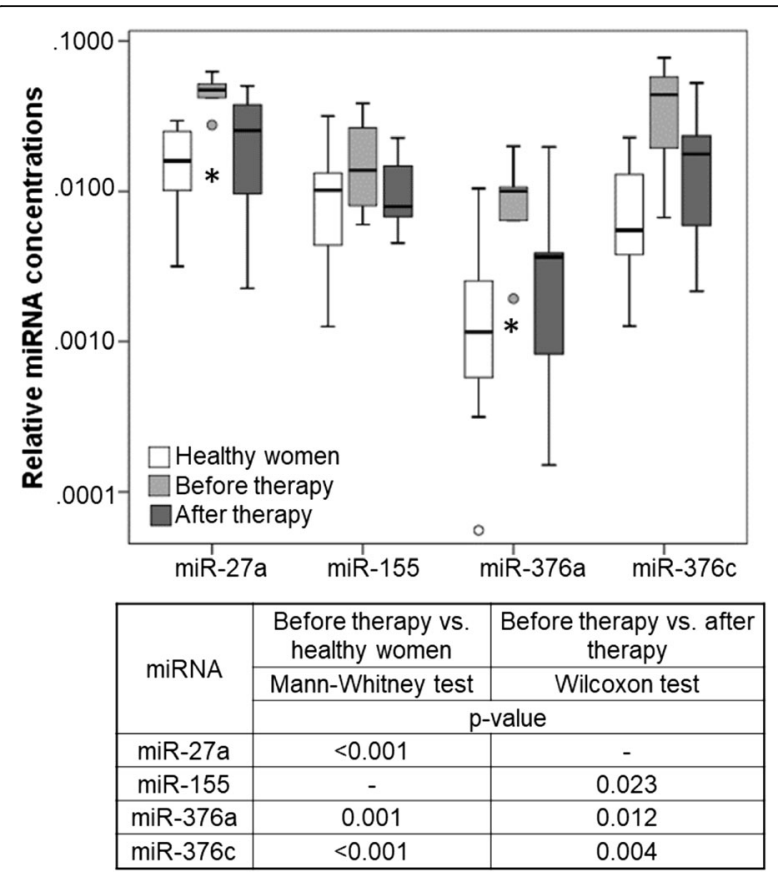

Fig. 4 Exosomal miRNA levels before and after neoadjuvant therapy. The box blot shows the plasma levels of exosomal miRNAs of $9 \mathrm{BC}$ patients before and after neoadjuvant therapy and 20 healthy women. $p$ values comparing the expression levels before and after therapy, and between patients and healthy women are indicated in the table below the blot. Cells filled with "-" denote insignificant correlations

patients $(p=0.023)$, while those of miR-328 were only upregulated in HER2-positive patients compared to healthy patients $(p=0.035$, Table 2$)$. In the subgroup of TNBC patients, only the levels of exosomal miR-374 were associated with higher tumor size, whereas in HER2-positive BC patients, the levels of 6 exosomal miRNAs (miR-185, miR-376a, miR-382, miR-410, miR-433, and miR-628) were associated with the tumor size (Table 3). These findings show the heterogeneity of both BC subtypes that is reflected by the subtype-specific miRNA expression or packaging of miRNAs into exosomes or both, and the relationship of these unique exosomal miRNA patterns with the diverse clinical parameters.

\section{Associations of exosomal miRNA levels with $\mathrm{PCR}$ and treatment arm}

Finally, univariate as well as multivariate (with covariables age, nodal status, tumor size and grading) logistic regression models for $\mathrm{pCR}$ were carried out in all patients and in the subgroups defined by TNBC patients, HER2positive patients, and patients in the carboplatin (pMCb) and non-carboplatin (pM) arm. Table 4 contains the unit odds ratio with $95 \%$ confidence interval and the corresponding Wald $p$ value for the miRNA variable in each model; model results are only reported if the uni- or multivariate model showed a significant contribution of the miRNA to the model, and only miRNAs contributing to all or the single subgroups are reported. At the beginning of our study quantifying exosomal miRNAs in plasma of 8 patients treated with carboplatin (4 with pCR and 4 without pCR), and 7 patients from the non-carboplatin arm (4 with $\mathrm{pCR}$ and 3 without $\mathrm{pCR}$ ) using the microRNA array containing 384 different miRNAs, we detected that the plasma levels of miR-199a $(p=0.036)$ differed between patients with and without $\mathrm{pCR}$, and the levels of miR-125 $(p=0.029)$, miR-193b $(p=0.029)$, miR-365 $(p=0.029)$ and miR-370 $(p=0.016)$ differed according to the treatment arm (data not shown). Now, in uni- and multivariate models comprising our large cohort of 435 patients including the single subgroups, the levels of exosomal miR-199a and the other 4 miRNAs did not correlate with $\mathrm{pCR}$ and the treatment arm, respectively, any more, suggesting that our starting patient cohort of 15 patients was too small to establish a significance of these exosomal miRNAs with pCR or treatment arm. In addition, the concentrations of no single miRNA in our set of 45 exosomal miRNAs were associated with the treatment arm, indicating that this set of miRNAs measured in pretreatment plasma samples cannot predict the treatment arm. However, 12 miRNAs could predict pCR in uni- or multivariate models comprising all patients or the single subgroups. Strikingly, the levels of miR-155 most significantly predicted pCR in uni- $(p=0.002)$ and multivariate model $(p=0.003)$ comprising all patients, as well as HER2-positive patients and TNBC patients (Table 4). This exosomal miRNA was also significantly downregulated in the 9 patients after therapy (Fig. $4 ; p=$ 0.023). Furthermore, the levels of miR-301 were also most significantly associated with pCR in uni- $(p=0.002)$ and multivariate model $(p=0.001)$ comprising all patients, as well as HER2-positive patients. Both the levels of miR-155 and miR-301 correlated somewhat better with PCR in the PMCb than PM arm (Table 4), indicating an improved response to carboplatin-based therapy.

\section{Discussion}

Molecular classification of $\mathrm{BC}$ into HER2-positive and TNBC tumors is essential for optimal use of current therapies and for development of new drugs. Of interest is that exosomes participate in cell-to-cell communication between cancer cells and normal host cells, and thus, are crucial components for regulation of the tumor microenvironment [20]. In this regard, investigation of the involvement of exosomal miRNAs of these tumors could provide new diagnostic/prognostic biomarkers and therapeutic target molecules, apart from a better understanding of tumor growth processes. In the current study, we identified miRNA signatures in exosomes specific to discriminate between HER2-positive and TNBC 
patients, indicating the different biology in these subgroups. Strikingly, different exosomal miRNA patterns were associated with the clinicopathological characteristics within the respective subgroups. As far as we know, this is the first study that measured a panel of $45 \mathrm{miR}$ NAs in exosomes derived from a large cohort of $435 \mathrm{BC}$ patients.

As we recently reported for ovarian cancer patients [21], we found that BC patients also had an excessive, active secretion of exosomes into their blood circulation. Although the levels of exosomes were somewhat higher in HER2-positive than TNBC patients, the difference was not significant. These findings suggest that a high secretion of exosomes may be a general feature of cancer patients. However, the exosomes differed in their content within both subgroups. Namely, we detected differently expressed miR-27a/b, miR-335, miR-365, miR-376c, miR-382, miR-422a, miR-433, and miR-628 in exosomes of either HER2-positive or TNBC patients compared with healthy women. This subtypespecific distribution of miRNAs in exosomes may indicate both, a different miRNA expression pattern and a selective exosomal packaging process. Based on the ability of exosomes to communicate between cells, the detection of these miRNA panels in exosomes may be superior to the detection of cell-free miRNAs in plasma or serum. To date, the presence of these miRNAs has not yet been described in BC-derived exosomes.

In our study, we detected that in comparison with healthy women, the levels of exosomal miR-27a were only significantly upregulated in HER2-positive patients (but not in TNBC patients), whereas the levels of miR-27b were upregulated in both subtypes, but with a significantly higher exosomal occurrence in HER2-positive patients. MiR-27a was reported to activate the Wnt/ $\beta$-catenin signaling pathway to promote the proliferation, migration, and invasion of BC cells [22]. So far, an association of miR-27a with HER2-positive BC has not been described. However, in contrast to our data an association of this miRNA with TNBC was revealed in a meta-analysis, but its quantification was carried out in tumor tissues and not in exosomes [23]. These findings possibly point to a selective packaging of miRNAs in exosomes independent of their expression levels. Conversely, our findings on the higher levels of exosomal miR-27b in HER2-positive patients are supported and complemented by the data by Jin et al. [24] showing that HER2 stimulated miR-27b expression through the $\mathrm{AKT} / \mathrm{NF}-\mathrm{\kappa B}$ signaling cascade. We also detected that the levels of exosomal miR-27b predict $\mathrm{pCR}$ in HER2-positive patients, indicating its narrow association with HER2-positive tumors. Despite the conventional role of miR-335 to act as a tumor suppressor in BC [25], our data demonstrate its significantly increased occurrence in exosomes from TNBC patients. Nevertheless,
Martin et al. [26] reported that miR-335 may also act in an oncogenic way in $\mathrm{BC}$, to repress genes involved in the ER $\alpha$ signaling pathway, and consequently, to enhance resistance to the growth inhibitory effects of tamoxifen. Contrary to our findings that show significantly upregulated levels of exosomal miR-365 in the subgroup of HER2-positive (but not in TNBC), miR-365 was reported to be downregulated and act as a tumor suppressor in BC. Kodahl et al. [27] showed that its expression levels were lower in serum of ER-positive BC patients than healthy controls, whereas we show that its levels in HER2-positive patients who do not express ER were increased. In addition, miR-365 was also described to be oncogenic. Overexpression of miR-365 promoted cell proliferation and invasion through targeting ADAMTS-1 (a disintegrin and metalloproteinase with thrombospondin motifs) in BC cells [28]. In our study, significantly higher levels of exosomal miR-376c and miR-382 were observed in TNBC patients, but not in HER2-positive BC patients. Upregulated levels of miR-376c [29] and miR-382 [30] were also detected in plasma and serum of $\mathrm{BC}$ patients (regardless of the subtypes), respectively, by two previous studies. In BC, miR-382 targeted and repressed the Ras GTPase superfamily member RERG (Ras-related and estrogenregulated growth inhibitor), to attenuate the inhibitory effects of RERG on the oncogenic Ras/ERK pathway. Thereby, miR-382 promoted BC cell viability, clonogenicity, survival, migration, invasion and in vivo tumorigenesis/metastasis [31]. Contrary, for example in oral squamous cancer, miR-376c seems to have tumor suppressive functions. Its overexpression in these cancer cells suppressed fission, proliferation, migration and invasion and induced cell apoptosis via targeting the transcription factor HOXB7 [32]. Finally, we found that the levels of exosomal miR-422a were downregulated in HER2-positive $\mathrm{BC}$ patients, whereas the levels of exosomal miR-433 were upregulated in TNBC patients, but till now, quantitative data on these miRNAs have not been published for BC patients. It was reported that in $\mathrm{BC}$ stem cells, upregulation of miR-422a attenuated microsphere formation, proliferation, and tumor formation via suppressing the PLP2 (Proteolipid protein 2) expression [33]. Moreover, miR-433 repressed Rap1a, a small G protein of the Ras guanosine triphosphatase (GTPase) superfamily that activates the MAPK signaling pathway, and thus repressed cell migration and proliferation and induced apoptosis in BC [34]. In addition, miR-433 targeted AKT3 in BC [35]. These findings highlight miR-422a and miR-433 as tumor suppressor genes.

Not only the miRNA patterns in exosomes differed between HER2-positive and TNBC patients, but they were also specifically associated with different clinicopathological parameters within the subgroups. For example, we identified a particular set of exosomal miRNAs (miR-16, 
miR-328, and miR-660) to be associated with lymph node status only in the subgroup of HER2-positive BC patients, but not in TNBC patients. In addition, we detected that miR-660 predicted pCR to neoadjuvant therapy in HER2-positive patients. Shen et al. already showed the potential of miR-660 as a therapeutic target for clinical treatment of $\mathrm{BC}$, and its role as a regulator of proliferation, migration, and invasion of human BC cells [36]. Moreover, our present findings on the association of the levels of exosomal miR-16 with lymph node status are substantiated by our previous data [37], demonstrating such an association with cell-free miR-16 in plasma. Thus, our findings indicate a possible role of miR-16 in the development of lymph node metastases in $\mathrm{BC}$. In the subgroup of TNBC patients, we discovered that only the levels of exosomal miR-374 were associated with a higher tumor size, whereas the levels of 6 exosomal miRNAs (miR-185, miR-376a, miR-382, miR-410, miR-433, and miR-628) showed such an association in HER2-positive BC patients. In addition, we revealed that miR-376a, those exosome-free plasma levels, are also upregulated in BC [29] displayed a dynamic presence in exosomes. Aside from miR-376a, three further miRNAs (miR-27a, miR-155, and miR-376c) were also downregulated to normal levels after neoadjuvant therapy, suggesting that these miRNAs may be released from the primary tumor into the blood to some extent, and their changes may directly reflect cancer status. Especially, miR-155 is a well-known miRNA with both tumor suppressive and oncogenic character, targeting, e.g., HER2 [38] and the transcription factor FOXO3a $[39,40]$ in $\mathrm{BC}$, respectively. Along with miR-27a, there is also an association of miR-155 with the decreased expression of FOXO3a which is paralleled with the increased expression of RUNX2 [41].

In neoadjuvant settings, the early identification of non-responding $\mathrm{BC}$ is crucial to avoid ineffective treatments. In particular for aggressive TNBC and HER2-positive $\mathrm{BC}$ subtypes, achievement of $\mathrm{pCR}$ correlates with improved long-term outcome [16, 42]. Here, we show for the first time that the levels of exosomal miR-155 in all $\mathrm{BC}$ patients and their subgroups, as well as exosomal miR-301 with the exception of triple-negative $\mathrm{BC}$ patients most significantly predicted $\mathrm{pCR}$ to neoadjuvant therapy. This information could be used for treatment stratification considering alternative treatment options. However, to introduce exosomal miR-155 and miR-301 as predictive markers, further prospective studies are necessary to confirm their predictive value. Particularly, the quantification of these exosomal miRNAs in a large cohort of plasma samples before, during, and after chemotherapy is required. Since miR-301 regulates the PTEN/Akt and NFKB signaling pathways that are important in the progression of $\mathrm{BC}[43,44]$, and binds to estrogen receptor 1 mRNA leading to estrogen independence of $\mathrm{BC}$ [45], miR-301 may be an early therapeutic target molecule in $\mathrm{BC}$.

To summarize, our findings suggest that certain miRNAs are selectively enriched in exosomes of HER2-positive and TNBC patients and are also associated with the clinicopathological parameters and $\mathrm{pCR}$ within the $\mathrm{BC}$ subtypes. Exosomal miRNAs may reflect the characteristics of their parental cells and, therefore, may offer a tumor-related profile. Recently, we found that the majority of miRNAs detectable in plasma is concentrated in exosomes [2]. However, it is of note to mention that the plasma exosome population is a heterogeneous mixture of cancer and normal (wild type) exosomes, and may be derived from all cells types, especially from blood cells. This, of course, compromises the tumor specificity of the identified exosomal miRNA signatures. Therefore, methods to selectively enrich cancer exosomes from plasma or serum have to be advanced. Unfortunately, tumor-associated exosome markers allowing such an enrichment are poorly defined. In addition, our unpublished data show that the proportion of tumor-derived exosomes is small in comparison with normal, wild-type exosomes impeding the isolation of low-abundant miRNAs. However, the extensive secretion of exosomes in $\mathrm{BC}$ patients triggered by the tumor points to that the tumor also communicates with wild-type exosomes. Thus, we should keep in mind that not only exosomes derived from the primary tumor or metastases may be eligible for cancer personalized diagnostics, but also exosomes derived from other organs that are affected by tumor burden [46].

Although our results show a different packaging of miRNAs into exosomes, and exosomal miRNAs as future diagnostic markers and therapeutic molecules, there are some aspects that may limit our study. Our analyses were carried out by miRNA array cards. We did not verify them by single real-time PCR assays, since the number of miRNAs was too high, and the population size too large in our study. However, our previous analyses in an independent cohort before starting the current study showed that the data were nearly congruent applying miRNA array cards and single real-time PCR analyses. In addition, the number of plasma samples collected directly after neoadjuvant therapy was too low, to make a statistical conclusion on the impact of therapy on the miRNA expression levels. However, the strength of our study is the number of miRNAs analyzed and the size of our patient population before neoadjuvant therapy.

\section{Conclusion}

Our data demonstrate differentially expressed and packaged miRNA sets in BC exosomes that could serve as potentially diagnostic and therapeutic markers for BC. These specific exosomal miRNA profiles that exclusively reflect HER2-positive and TNBC as well as the different 
stages of $\mathrm{BC}$ may provide insight into the exosome biology for monitoring the disease. Further analyses are planned to analyze the significantly deregulated exosomal miRNAs in a higher number of plasma samples collected after treatment as well as in follow-up studies. Finally, a detailed investigation on their association with $\mathrm{pCR}$ and treatment arms is required.

\section{Additional file}

Additional file 1: Figure S1. Levels of free hemoglobin were measured in plasma samples by spectrophotometry at wavelengths from 350 to $650 \mathrm{~nm}$. A dilution series of lysed red blood cells in plasma was prepared (below the chart). The degree of hemolysis was determined based on the optical density (OD) at $414 \mathrm{~nm}$ (absorbance peak of free hemoglobin, called Soret band), with additional peaks at 541 and $576 \mathrm{~nm}$. Samples were classified as being hemolysed if the OD at 414 exceeded 0.25 . The integrated curve of BC plasma samples comprises values from 0.08 to 0.20 indicating that the samples were non-hemolysed. Figure S2. Hierarchical cluster is shown by heat map of median centered $\Delta C q$ values of exosomal. miRNAs (in rows) derived from plasma samples of $435 \mathrm{BC}$ patients before treatment and 20 healthy women (in columns). The red and green colors indicate that the $\Delta C q$ values are below (relatively high expression) and above (relatively low expression levels) the median of all $\Delta C q$ values in the study, respectively. Bottom: clustering of samples. Left: clustering of probes. The scale bar provides information on the degree of regulation. The 5 clinically relevant miRNAs derived from the microRNA array cards containing 384 different miRNAs are indicated by a red arrow. Figure S3. Exosomal miRNAs differ between HER2-positive and TNBC patients. ROC analyses show the profiles of sensitivity and specificity of exosomal miR-335, miR-422a, and miR-628 and their combinations to distinguish TNBC from HER2-positive $\mathrm{BC}$ patients. The table below the ROC shows the summarization of sensitivities and specificities of exosomal miR-335, miR-422a, miR-628, and their combinations. Table S1. Patient characteristics at the time of primary diagnosis of breast cancer (continuous variables). Table S2. Significant associations between the plasma levels of exosomal miRNAs and clinicopathological risk parameters (continuous variables). (ZIP $2140 \mathrm{~kb})$

\section{Abbreviations}

3'UTR: 3' Untranslated-region; ADAMTS-1: A disintegrin and metalloproteinase with thrombospondin motifs; AUC: Area under the curve; BC: Breast cancer; ER: Estrogen receptor; HER2: Human epidermal growth factor receptor 2; miRNA: MicroRNA; pCR: Pathological complete response; pM: Non-carboplatin arm; pMCb: Carboplatin arm; PR: Progesterone receptor; RERG: Ras-related and estrogen-regulated growth inhibitor; ROC: Receiver operating characteristic; TNBC: Triple-negative breast cancer

\section{Acknowledgements}

We thank Ms. Bettina Steinbach for her excellent technical assistance, Dr. Antonio Virgilio Failla for microscopy, and Dr. Tanja Zeller's lab for using the PCR block. We are also grateful to Dr. Christian Pick (Thermo Fisher Scientific), who helped us to carry out the statistical evaluation of our data. We also thank Prof. Dr. Hans Joachim Seitz for his kind assistance during the stay of Ines Stevic.

\section{Funding}

This work was supported by the Wilhelm Sander Stiftung, Munich, Germany, and Walter Schulz-Stiftung, Planegg/Martinsried, Germany.

\section{Availability of data and materials}

All data generated or analyzed during this study are included in this published article and its supplementary information files.

\section{Authors' contributions}

IS performed experiments. HS, IS, and VM designed the study. PAF, TK, FM, $C S, E S, C D, M M, C S, A S, S L$, and $M U$ provided the plasma samples and clinical data. HS, IS, and KW analyzed and interpreted the measured data. HS and IS wrote and revised the manuscript. HS, KW, VM, IS, and KP reviewed the manuscript. KW performed the statistics. HS supervised the study. All authors read and approved the final manuscript.

\section{Ethics approval and consent to participate}

The local ethics committee (Ethik-Kommission der Ärztekammer Hamburg, Hamburg) approved this study. All patients gave written informed consent according to the Helsinki declaration.

\section{Consent for publication}

Not applicable.

\section{Competing interests}

The authors declare that they have no competing interests.

\section{Publisher's Note}

Springer Nature remains neutral with regard to jurisdictional claims in published maps and institutional affiliations.

\section{Author details}

${ }^{1}$ Department of Tumor Biology, University Medical Center Hamburg-Eppendorf, Martinistraße 52, 20246 Hamburg, Germany. ${ }^{2}$ Department of Gynecology, University Medical Center Hamburg-Eppendorf, Hamburg, Germany. ${ }^{3} \mathrm{GBG}$ Forschungs GmbH, Neu-lsenburg, Germany. ${ }^{4}$ Department of Gynecology and Obstetrics, University Hospital Erlangen, Comprehensive Cancer Center Erlangen-EMN, Friedrich-Alexander University Erlangen-Nuremberg, Erlangen, Germany. ${ }^{5}$ University Women's Hospital, Frankfurt, Germany. ${ }^{6}$ Center for Gynecological Oncology at University Women's Hospital, Heidelberg, Germany. ${ }^{7}$ Mammazentrum Hamburg, Hamburg, Germany. ${ }^{8}$ Universitätsklinikum Aachen, Aachen, Germany. ${ }^{9}$ Charite Berlin, Institute of Pathology and German Cancer Consortium (DKTK), Partner Site, Berlin, Germany. ${ }^{10}$ Universitätsklinikums Schleswig-Holstein Kiel, Kiel, Germany. ${ }^{11}$ Hämatoonkologische Schwerpunktpraxis, Munich, Germany. ${ }^{12}$ Universitätsklinikum Heidelberg, Heidelberg, Germany. ${ }^{13}$ Helios Kliniken Berlin-Buch, Berlin, Germany.

Received: 10 April 2018 Accepted: 30 August 2018

Published online: 10 October 2018

\section{References}

1. Strehl JD, Wachter DL, Fasching PA, Beckmann MW, Hartmann A. Invasive breast cancer: recognition of molecular subtypes. Breast Care (Basel). 2011; 6(4):258-64

2. Eichelser C, Stuckrath I, Muller V, Milde-Langosch K, Wikman H, Pantel K, et al. Increased serum levels of circulating exosomal microRNA-373 in receptor-negative breast cancer patients. Oncotarget. 2014;5(20):9650-63.

3. Schwarzenbach $\mathrm{H}$. Circulating nucleic acids as biomarkers in breast cancer. Breast Cancer Res. 2013;15(5):211.

4. Calin GA, Sevignani C, Dumitru CD, Hyslop T, Noch E, Yendamuri S, et al. Human microRNA genes are frequently located at fragile sites and genomic regions involved in cancers. Proc Natl Acad Sci U S A. 2004; 101(9):2999-3004

5. Bartel DP. MicroRNAs: target recognition and regulatory functions. Cell. 2009;136(2):215-33.

6. Mitchell PS, Parkin RK, Kroh EM, Fritz BR, Wyman SK, Pogosova-Agadjanyan EL, et al. Circulating microRNAs as stable blood-based markers for cancer detection. Proc Natl Acad Sci U S A. 2008:105(30):10513-8.

7. Stroun M, Lyautey J, Lederrey C, Olson-Sand A, Anker P. About the possible origin and mechanism of circulating DNA apoptosis and active DNA release. Clin Chim Acta. 2001;313(1-2):139-42.

8. Turchinovich A, Weiz L, Langheinz A, Burwinkel B. Characterization of extracellular circulating microRNA. Nucleic Acids Res. 2011;39(16):7223-33.

9. Pant S, Hilton H, Burczynski ME. The multifaceted exosome: biogenesis, role in normal and aberrant cellular function, and frontiers for pharmacological and biomarker opportunities. Biochem Pharmacol. 2012;83(11):1484-94.

10. Schwarzenbach $\mathrm{H}$. The clinical relevance of circulating, exosomal miRNAs as biomarkers for cancer. Expert Rev Mol Diagn. 2015;15(9):1159-69.

11. Simpson RJ, Lim JW, Moritz RL, Mathivanan S. Exosomes: proteomic insights and diagnostic potential. Expert Rev Proteomics. 2009;6(3):267-83. 
12. Valadi H, Ekstrom K, Bossios A, Sjostrand M, Lee JJ, Lotvall JO. Exosomemediated transfer of mRNAs and microRNAs is a novel mechanism of genetic exchange between cells. Nat Cell Biol. 2007;9(6):654-9.

13. Chen $\mathrm{X}$, Liang $\mathrm{H}$, Zhang J, Zen $\mathrm{K}$, Zhang CY. Horizontal transfer of microRNAs: molecular mechanisms and clinical applications. Protein Cell. 2012;3(1):28-37.

14. Lee TH, D'Asti E, Magnus N, Al-Nedawi K, Meehan B, Rak J. Microvesicles as mediators of intercellular communication in cancer--the emerging science of cellular 'debris. Semin Immunopathol. 2011;33(5):455-67.

15. Howcroft TK, Zhang HG, Dhodapkar M, Mohla S. Vesicle transfer and cell fusion: Emerging concepts of cell-cell communication in the tumor microenvironment. Cancer Biol Ther. 2011;12(3):159-64

16. von Minckwitz G, Schneeweiss A, Loibl S, Salat C, Denkert C, Rezai M, et al. Neoadjuvant carboplatin in patients with triple-negative and HER2-positive early breast cancer (GeparSixto; GBG 66): a randomised phase 2 trial. Lancet Oncol. 2014;15(7):747-56.

17. Kirschner MB, Kao SC, Edelman JJ, Armstrong NJ, Vallely MP, van Zandwijk $\mathrm{N}$, et al. Haemolysis during sample preparation alters microRNA content of plasma. PLoS One. 2011;6(9):e24145.

18. Schwarzenbach $\mathrm{H}$, da Silva AM, Calin G, Pantel K. Data Normalization Strategies for MicroRNA Quantification. Clin Chem. 2015;61(11):1333-42.

19. Sharma NR, Wang X, Majerciak V, Ajiro M, Kruhlak M, Meyers C, et al. Cell type- and tissue context-dependent nuclear distribution of human Ago2. J Biol Chem. 2016;291(5):2302-9.

20. Zhao L, Liu W, Xiao J, Cao B. The role of exosomes and "exosomal shuttle microRNA" in tumorigenesis and drug resistance. Cancer Lett. 2015;356(2 Pt B):339-46.

21. Meng X, Muller V, Milde-Langosch K, Trillsch F, Pantel K, Schwarzenbach H. Diagnostic and prognostic relevance of circulating exosomal miR-373, miR200a, miR-200b and miR-200c in patients with epithelial ovarian cancer. Oncotarget. 2016;7(13):16923-35.

22. Kong LY, Xue M, Zhang QC, Su CF. In vivo and in vitro effects of microRNA$27 \mathrm{a}$ on proliferation, migration and invasion of breast cancer cells through targeting of SFRP1 gene via Wnt/beta-catenin signaling pathway. Oncotarget. 2017;8(9):15507-19

23. Lu L, Mao X, Shi P, He B, Xu K, Zhang S, et al. MicroRNAs in the prognosis of triple-negative breast cancer: a systematic review and meta-analysis. Medicine (Baltimore). 2017:96(22):e7085.

24. Jin L, Wessely O, Marcusson EG, Ivan C, Calin GA, Alahari SK. Prooncogenic factors miR-23b and miR-27b are regulated by Her2/Neu, EGF, and TNFalpha in breast cancer. Cancer Res. 2013;73(9):2884-96.

25. Bertoli G, Cava C, Castiglioni I. MicroRNAs: new biomarkers for diagnosis, prognosis, therapy prediction and therapeutic tools for breast cancer. Theranostics. 2015;5(10):1122-43.

26. Martin EC, Conger AK, Yan TJ, Hoang VT, Miller DF, Buechlein A, et al. MicroRNA-335-5p and -3p synergize to inhibit estrogen receptor alpha expression and promote tamoxifen resistance. FEBS Lett. 2017;591(2):382-92.

27. Kodahl AR, Lyng MB, Binder H, Cold S, Gravgaard K, Knoop AS, et al. Novel circulating microRNA signature as a potential non-invasive multi-marker test in ER-positive early-stage breast cancer: a case control study. Mol Oncol. 2014:8(5):874-83.

28. Li M, Liu L, Zang W, Wang Y, Du Y, Chen $X$, et al. miR365 overexpression promotes cell proliferation and invasion by targeting ADAMTS- 1 in breast cancer. Int J Oncol. 2015:47(1):296-302.

29. Cuk K, Zucknick M, Madhavan D, Schott S, Golatta M, Heil J, et al. Plasma microRNA panel for minimally invasive detection of breast cancer. PLoS One. 2013:8(10):e76729.

30. Mar-Aguilar F, Mendoza-Ramirez JA, Malagon-Santiago I, Espino-Silva PK, Santuario-Facio SK, Ruiz-Flores P, et al. Serum circulating microRNA profiling for identification of potential breast cancer biomarkers. Dis Markers. 2013;34(3):163-9.

31. Ho JY, Hsu RJ, Liu JM, Chen SC, Liao GS, Gao HW, et al. MicroRNA-382-5p aggravates breast cancer progression by regulating the RERG/Ras/ERK signaling axis. Oncotarget. 2017;8(14):22443-59.

32. Wang K, Jin J, Ma T, Zhai H. MiR-376c-3p regulates the proliferation, invasion, migration, cell cycle and apoptosis of human oral squamous cancer cells by suppressing HOXB7. Biomed Pharmacother. 2017:91:517-25.

33. Zou Y, Chen Y, Yao S, Deng G, Liu D, Yuan X, et al. MiR-422a weakened breast cancer stem cells properties by targeting PLP2. Cancer Biol Ther. 2018;19(5):436-44
34. Zhang T, Jiang K, Zhu X, Zhao G, Wu H, Deng G, et al. miR-433 inhibits breast cancer cell growth via the MAPK signaling pathway by targeting Rap1a. Int J Biol Sci. 2018;14(6):622-32.

35. Hu X, Wang J, He W, Zhao P, Ye C. MicroRNA-433 targets AKT3 and inhibits cell proliferation and viability in breast cancer. Oncol Lett. 2018; 15(3):3998-4004.

36. Shen Y, Ye YF, Ruan LW, Bao L, Wu MW, Zhou Y. Inhibition of miR-660-5p expression suppresses tumor development and metastasis in human breast cancer. Genet Mol Res. 2017;16(1).

37. Stuckrath I, Rack B, Janni W, Jager B, Pantel K, Schwarzenbach H. Aberrant plasma levels of circulating miR-16, miR-107, miR-130a and miR-146a are associated with lymph node metastasis and receptor status of breast cancer patients. Oncotarget. 2015;6(15):13387-401.

38. He XH, Zhu W, Yuan P, Jiang S, Li D, Zhang HW, et al. miR-155 downregulates ErbB2 and suppresses ErbB2-induced malignant transformation of breast epithelial cells. Oncogene. 2016;35(46):6015-25.

39. Kong W, He L, Coppola M, Guo J, Esposito NN, Coppola D, et al. MicroRNA155 regulates cell survival, growth, and chemosensitivity by targeting FOXO3a in breast cancer. J Biol Chem. 2010;285(23):17869-79.

40. Yamamoto M, Kondo E, Takeuchi M, Harashima A, Otani T, Tsuji-Takayama K, et al. miR-155, a modulator of FOXO3a protein expression, is underexpressed and cannot be upregulated by stimulation of HOZOT, a line of multifunctional Treg. PLoS One. 2011;6(2):e16841.

41. Jurkovicova D, Magyerkova M, Sestakova Z, Copakova L, Bella V, Konecny M, et al. Evaluation of expression profiles of microRNAs and two target genes, FOXO3a and RUNX2, effectively supports diagnostics and therapy predictions in breast cancer. Neoplasma. 2016;63(6):941-51.

42. von Minckwitz G, Loibl S, Untch M, Eidtmann H, Rezai M, Fasching PA, et al. Survival after neoadjuvant chemotherapy with or without bevacizumab or everolimus for HER2-negative primary breast cancer (GBG 44GeparQuinto)dagger. Ann Oncol. 2014;25(12):2363-72.

43. Shi W, Gerster K, Alajez NM, Tsang J, Waldron L, Pintilie M, et al. MicroRNA301 mediates proliferation and invasion in human breast cancer. Cancer Res. 2011;71(8):2926-37.

44. Ma F, Zhang J, Zhong L, Wang L, Liu Y, Wang Y, et al. Upregulated microRNA-301a in breast cancer promotes tumor metastasis by targeting PTEN and activating Wnt/beta-catenin signaling. Gene. 2014:535(2):191-7.

45. Lettlova S, Brynychova V, Blecha J, Vrana D, Vondrusova M, Soucek P, et al MiR-301a-3p suppresses estrogen signaling by directly inhibiting ESR1 in ERalpha positive breast cancer. Cell Physiol Biochem. 2018;46(6):2601-15.

46. Roccaro AM, Sacco A, Maiso P, Azab AK, Tai YT, Reagan M, et al. BM mesenchymal stromal cell-derived exosomes facilitate multiple myeloma progression. J Clin Invest. 2013;123(4):1542-55.

Ready to submit your research? Choose BMC and benefit from

- fast, convenient online submission

- thorough peer review by experienced researchers in your field

- rapid publication on acceptance

- support for research data, including large and complex data types

- gold Open Access which fosters wider collaboration and increased citations

- maximum visibility for your research: over $100 \mathrm{M}$ website views per year

At $\mathrm{BMC}$, research is always in progress.

Learn more biomedcentral.com/submission 